\title{
應用移植方法產生的分枝大麥
}

\author{
丁振嶙汪麗泉，
}

(浙江大學贯蓺系)

\section{一 引}

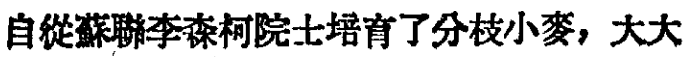
的提高了小麥的產量以後,關於运類問題的研究, 已廣泛地引起了我國農栄科舉工作者的重視。

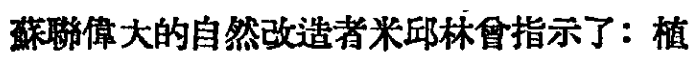
物在新的生活條件下, 可以獲得新的生物特性,我

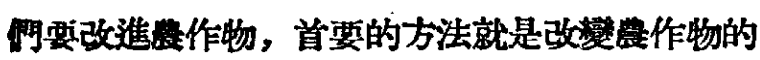
珢境條件,使它向着人類所需要的方向改變，然後

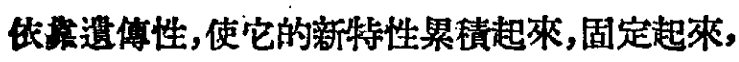
成第對人類有利盆的新的植物品系。

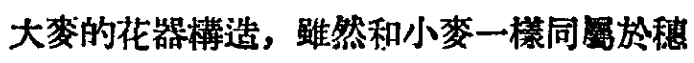
狀花序，但小梦穗的每一小穗内可以有幾架花，結

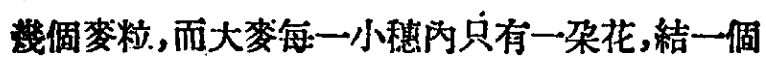
娄柆, 所以在大娄穗構造的特性上,希空它的商量 㘿加是受渚限制的,然而在理論上, 假若我們改變

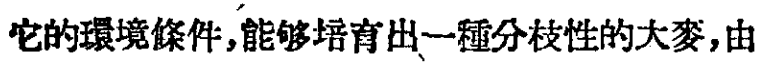
於分枝的加多; 使每糟的梦粒數目㙞加，那末它的 量自然可以大大的提高了。

關知分枝大麥的应生，國內外還很少有人研 究過，葆㬝普列森特會用低温，長日照和肥培的佟 件彪理下，引起了大麥的分枝型，此外趋傳集也曾 在山東東海踶崑崙縣绻家田內發現過兩個分枝的 大麥䅹。

我阿都知道，小秋應用移植方法是可以坦加

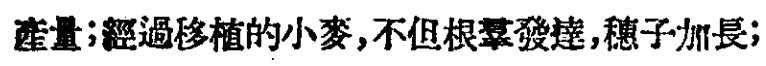

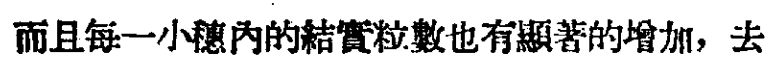
年我門仿照小麥的移植法, 做了一個二稜大麥的 移植試驗，二棱大麥是杭州農家裁培最廣的品種， 我們希害配合移植方法和其他裁培技街來㙁加大

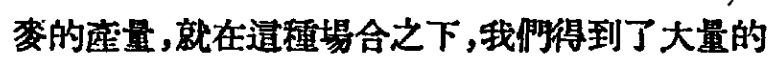
分枝大娄。
經過移植以後的大麥,根样特别䓝達, 苗集的

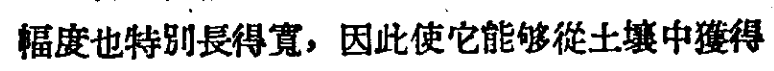

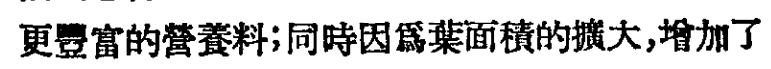
它的同化作用, 這是給予大梦累䘽營養物留極有 利的條件，但是由於大麥每一小惠內的結管粒数 受了限制, 篇了要充分利用這些累積的養分, 不得 不在穗子的基部或中部号兴分枝, 於是就形成了 分枝大梦,這與米邱林的改變栈培修件,使植物的 某程特性發生改變的理由是完全相符合的。

\section{二 從移植载培中所貛得分枝大麥的類型}

我椚在試驗區內所見到的分枝型大梦可分篇 三類，現在特各種類型分別叙述於下:

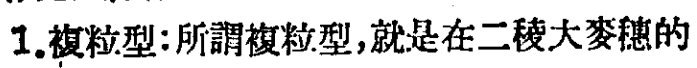
基部, 偶然生出二三個小䦄,成媱额外的程子，造

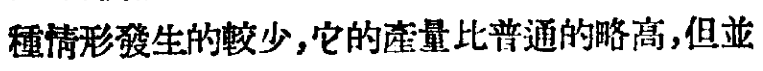

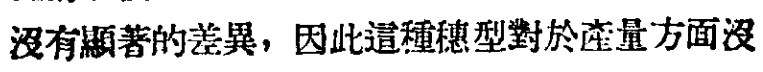
有很大的價值。

2.分枝型：分枝型大梨是在大秋穗的基部或 中部長出各秏不同程度的分枝來(見圖一), 它的

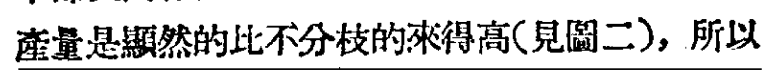

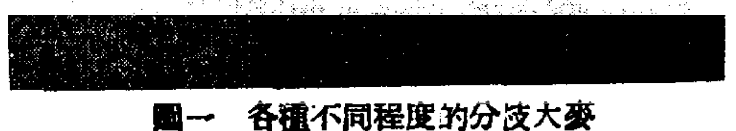




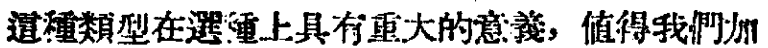

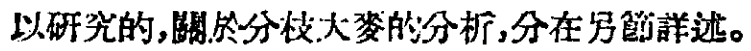

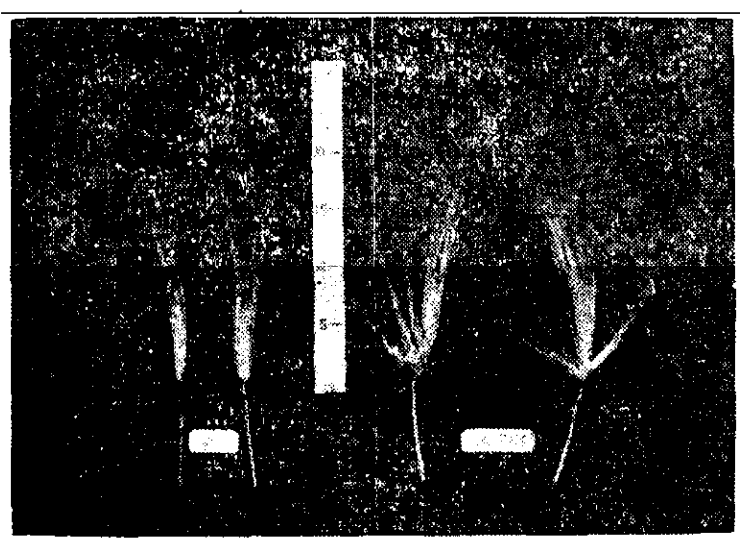

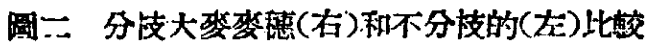

3.留悡型:除椱煜型,分枝型以外，還有一電

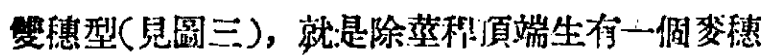

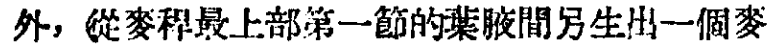

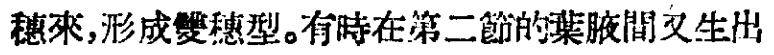

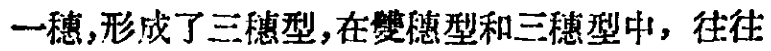

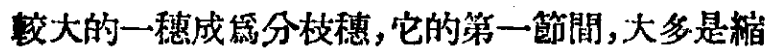
短而扭明的，這是因简䇣穗型在登育的初期，穗型 就比較大, 當抽愁時, 包著在葉䩗內很不容易抽 出，因此麥程受了厥力,戀成了主曲㭊。

留穗型 在晚期的移植 大麥 中得生的数量較 多，因齋晚期移植的大麥分苝較少，由於移植所累

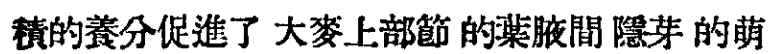

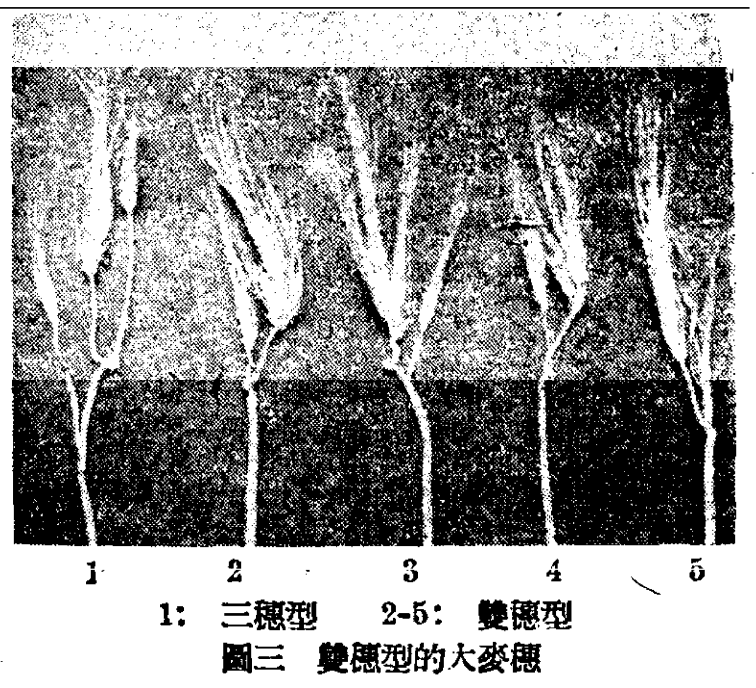

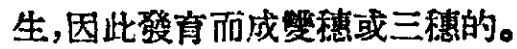

\section{三 分枝大麥的分析}

- 1.分枝大梦的椿造:分枝大麥的分枝，一般都

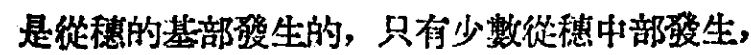
分枝的数目從一僻到五六倜不等。每一分枝,多的 有二十秘絃子，少的只有面五料。分枝所結的種 粒大多比主穗上所生的略小，但也有少数反而狳 㴖些的。及分枝大婪的漷积!比較短而粗壯，所以不 容易倒伏，這是一般經過移植的大娄所共有的便 向。

\section{2.分枝大麥麥䄼的統計分析：}

\section{第 一 表}

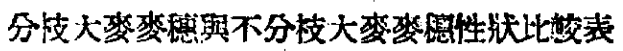

\begin{tabular}{|c|c|c|c|c|c|c|c|}
\hline & 洘查梏数 & 糟軍(g) & 分枝数 & 總小锚數 & 結菑煜数 & $\begin{array}{r}\text { 每琶粒重 } \\
(\mathrm{g})\end{array}$ & 千粒重 \\
\hline 二稜分枝大零 & 50 & 2.28 & 2.4 & 55.30 & $4 \overline{5} .16$ & $18.6 \%$ & 41.2 \\
\hline 二酸 大 麥 & 10 & 1.79 & - & 34.20 & 32.00 & 15.80 & 47.8 \\
\hline 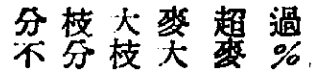 & , & 27.37 & & 61.69 & 41.12 & 21.69 & -15.95 \\
\hline
\end{tabular}

從上表挠個性状考查的結果來看, 分伎大桨 的平均穗重，總小穗數，結货垃數，每穗粒重都有

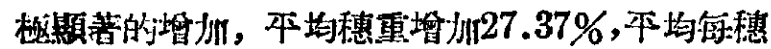
粒重增州 $21.69 \%$,這就是說如果將來能培育一㻎

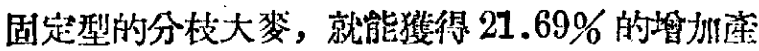

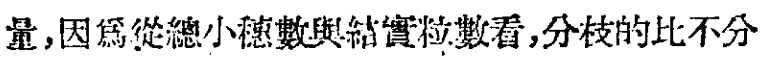
枝的望高得多，但因分枝大皎結算不及不分枝的

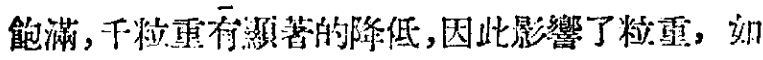

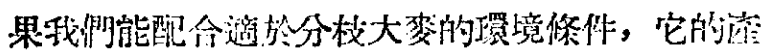

量是可以更大的提高的。

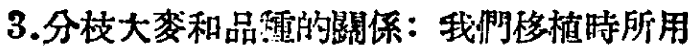
的有雨個品種，一個是杭州二稜大慗，一個是杭州

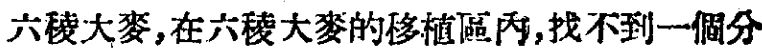

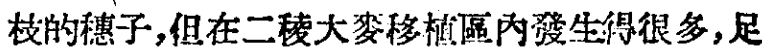
見品種不同，主草了分枝期不分枝的重要因素，然

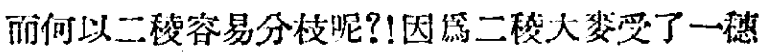

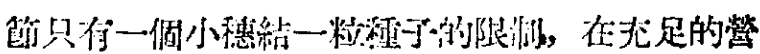

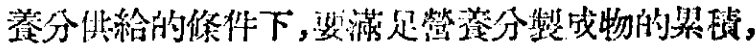


可能促進了分枝的發生，或者可以說二稜大麥是 比較富於游重性的原故。

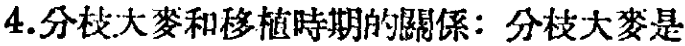
在移植區中酒生的,在通播區中，還级有發現分枝

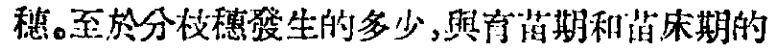
展短有一定进的關係:

$$
\text { 第 二 表 }
$$

大麥充㳻期

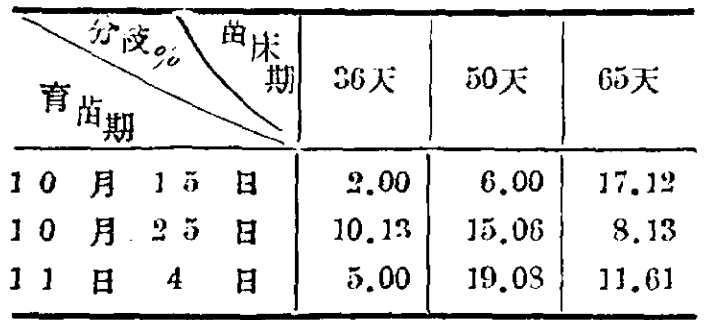

從上表看束，育萌期的延䢰，和苗休期的增

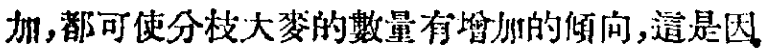

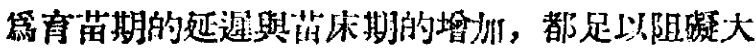

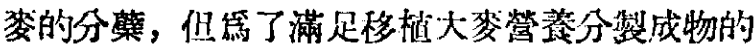

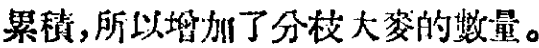

\section{四 緒結和期望}

從蘇聯李森科院士對於分枝小装研究的数㴧

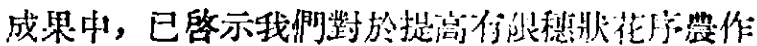

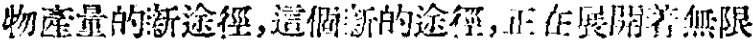
的柀啧。

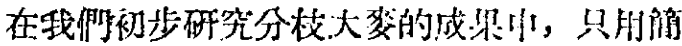

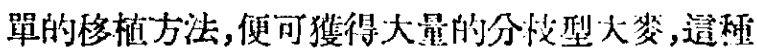

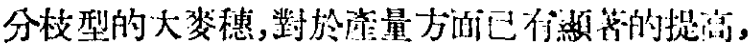
並且具往学积不易倒伏的優良性将。

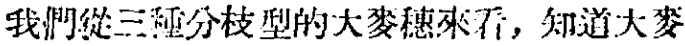

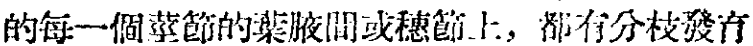

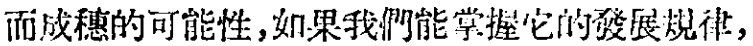

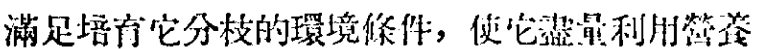

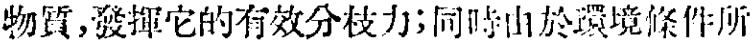

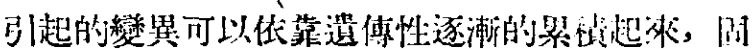

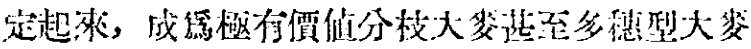

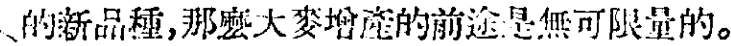

\section{中國化學會確定爲國防經濟建設服務的方針}

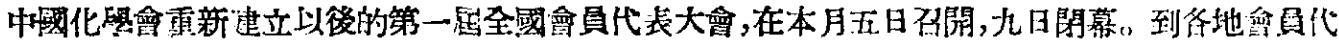

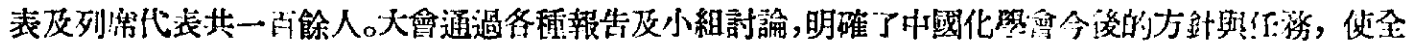

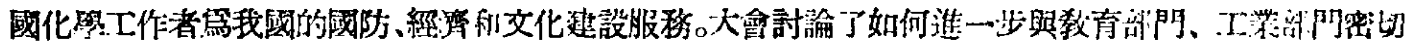

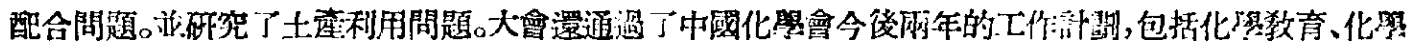

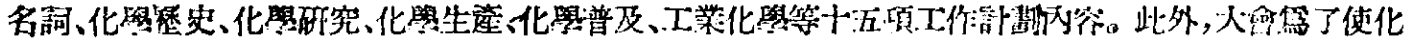

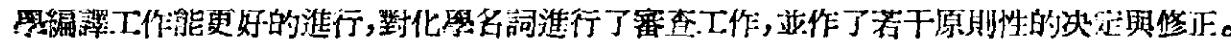

\section{(人民日趣 8 月17日)}

\section{中國生理學會討論軍糧製造等問題}

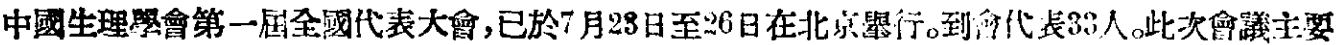

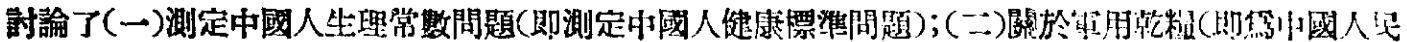

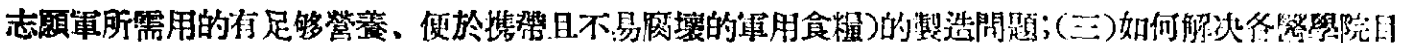

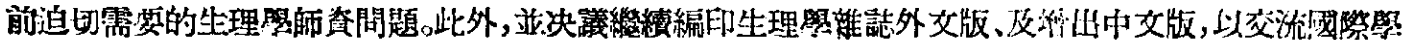
街及生理學知識。

(人比日報 8 月17日) 